1. Métodos patrimonicis, 2. Valor de liquidação;

3. Valor pela projeção de lucros passidos;

4. Valor das açues;

5. Vulor atual de lucros juturos; 6. Conclusico.

Wolfgang Schoeps*

* Professor e Chefe do

Departamento de Produção da Escola de Administração de Empresas de São Paulo da Fundação Getulio Vargas.
Nos métodos de avaliação de um empreendimento econômico, o critério da rentabilidade está substituindo a mera avaliação patrimonial. Para os investidores em ações também é essencial o conhecimento do valor da empresa a fim de examinar o preço dos títulos em bases reais.

A problemática da avaliação de um empreendimento econômico, isto é, a determinação do valor de una empresa, constitui-se em tarefa clássica para profissiona is nos mais diversos campos: economistas, administradores, contadores, engenheiros, analistas de investimentos, banqueiros e empresários. Tratando-se freqüentemente de situações que vão resultar en uma futura negociação, quer de toda a empresa, quer de parte de suas açôes, $\hat{e}$ apenas natural que grandes divergências possam surgir entre as análises feitas pelas partes envolvidas. Em absoluto, isto näo significa que os procedimentos adotados näo sejam honestos, porém, face à multiplicidade de métodos, os resultados da avaliação podem variar grandemente, a ponto de confundir facilmente os leigos no assunto. Além disso, o processo inflacionário contribui para introduzir distorcōes, que muitas vezes não são adequadtamente corrigidas e analisadas.

Os objetivos do investidor sempre podem ser resumidos em dois pontos: segurança e rentabilidade. Quanto d̀ última, apresenta-se ainda sob duas formas, a saber, a lucratividade corrente, resultante das operaçóes efetuadas durante cada excrcicio, e o lucro obtido por eventual valorização patrimonial, isto $\dot{e}$, o lucro obtido no momento da venda do investimento, face ao aumento de seu valor inicial. Assim, por exemplo, ainda que os lucros anuais de uma empresa tenham sido muito reduzidos, é perfeitamente possivel auferir clevado lucro ao final de um certo periodo, desde que na hora da venda apareçam compradores dispostos a pagar um preço real muito superior ao investimento original. Desse modo, teria ocorrido uma valorização patrimonial, resultando em lucros, os quais, diga-se de passagem, são geralmente não tributáveis para a pessoa física. Poltanto, o lucro resultante da valorização patrimonial é sempre o preferido pelos investidores. De certo modo, esse fenômeno pode ser observado nas Bolsas de Valores, onde é relativamente mais reduzido $o$ interesse pelo recebimento de dividendos, os quais representam uma porcentagem pouco significativa em relaçâo ao valor das açôes, especialmente no caso das de preço mais alto, do que 0 interesse pela subida das cotações que é de importância primordial. Os empresários inteligentes visam primordialmente a constante vaIorização de sua empresa, mediante apresentação

R. Adm. Emp., Rio de Janeiro,

$12,4,: 69.72$

out./dez. 1972 
de uma performance operacional favorável, nos relatórios anuais.

$\mathrm{Na}$ prática das operaçōes de Bolsa, o processo de determinação do valor de uma empresa é apenas parcialmente ligado à sua lucratividade, pois, fatores de oferta e procura das açōes, inclusive de caráter especulativo, freqüentemente modificam totalmente o preço das açōes que, do ponto de vista econômico, deveria resultar de um processo de avaliação do valor atual do empreendimento. A médio e longo prazo, porém, os preços dessas açōes deverão forçosamente ajustar-se ao valor efetivo do objeto do investimento, que é a empresa. As distorçōes, que por natureza são efêmeras, tendem sempre para sua correção, pelo natural domínio da realidade econômica.

Para demonstrar a discrepância existente entre os diversos métodos de determinação do valor de uma empresa, convém analisar aqui, ainda que de modo sucinto, seus procedimentos e suas respectivas bases conceituais.

\section{Métodos patrimoniais}

Esses métodos tomam por base de valor da empresa o respectivo valor de patrimônio liquido, constituído pelo capital mais as reservas. Como a contrapartida do capital é representada por diversas posiçōes no ativo, especialmente o imobilizado e os estoques, é pela avaliação destes últimos que se chega, finalmente, à fixação do valor do patrimônio líquido para determinada empresa. Diferentes resultados poderão ser obtidos, pois os métodos de avaliação do ativo imobilizado podem divergir grandemente, inclusive em virtude de determinaçōes legais, resultando em distorções face à realidade econômica.

Fundamentalmente, convëm examinar, quanto a esse particular, cinco métodos patrimoniais:

\subsection{VALOR HISTORICO}

O patrimônio líquido é determinado, neste caso, em função de valores do imobilizado.em bases históricas, isto é, valores registrados na data da aquisição dos bens, deduzindo-se a depreciação efetuada anualmente. Face à inflação, esses valores estão desatualizados e não traduzem mais valores reais, os quais deveriam ter nova expressão monetária. Os exemplos mais conhecidos de valores históricos são os dos bens do Bancó do Brasil e da Petrobrás, empresas para as quais não é permitida a reavaliação anual do ativo, a não ser por ato especifico do Governo, e sempre em faixas muito aquém da taxa dẻ inflação.

\subsection{VALOR REAVALIADO}

Neste caso, o valor do ativo imobilizado, com conseqüente reflexo na estrutura de capital da empresa, está sujeito à correção monetária anual, de acordo com os índices publicados pelo Ministério do Planejamento. Observe-se que a correção monetária atinge também as depreciaçōes efetuadas.

\subsection{VALOR DE MERCADO}

Determina-se o valor de mercado dos bens da empresa, isto é, o possível preço a ser obtido na venda de seu imobilizado, como terrenos, edificaçōes, máquinas, equipamentos, e dos estoques de materiais e produtos acabados. $O$ valor de mercado pode situar-se tanto acima como abaixo dos valores contabilizados, isto é, dos valores reavaliados, e reduzidos pela depreciação anual.

\subsection{VALOR DE REPOSIÇÃO}

O valor de reposição ou reprodução é representado pelo montante que seria hoje necessário para reproduzir todos os bens do ativo da empresa, tais como instalaçōes e estoques. Esses valores divergem freqüentemente dos valores reavaliados, pois, os custos de reprodução podem ultrapassar de maneira considerável o montante obtido por correção monetária. Note-se que esta última, por definição, está defasada sempre de um ano, significando reduçāo a priori de $20 \%$ do valor atual. Ainda recentemente, o presidente de uma das principais indústrias automobilisticas do país afirmou que o valor de reposiçáo de seu ativo fixo representa o dobro do valor reavaliado e registrado no balanço da empresa.

\subsection{VALOR PATRIMONIAL ACRESCIDO DO FUNDO DE COMERCIO}

O valor patrimonial líquido, obtido por um dos métodos anteriores, pode ser acrescido de determinada quantia, correspondente a valores intangiveis, representados por direitos de concessão, patentes e marcas, ponto comercial, tradição e itens semelhantes, constituindo o "Fundo de Comércio". E a "mais-valia" decorrente da existência do negócio como going büsiness, isto é, como empresa em pleno funcionamento e de posição firmada no mercado.

\section{Valor de liquidação}

Esse método preconiza a elaboração do chamado "balanço de liquidação", isto é, do balanço que representaria a situação resultante do eventual encerramento das atividades empresariais. Esta 
hipótese admite diversos pressupostos. A alienação dos bens está evidentemente sujeita aos preços de mercado, geralmente divergentes dos valores contábeis. Caso resulte da liquidação do ativo um valor em excesso, diz-se que existe um "ativo oculto". $\mathbf{E}$ o caso típico da venda de terrenos, cujo valor de mercado ultrapassa o valor reavaliado. Outro exemplo pode ser representado pela venda de ações, isto é, participaçōes em outras empresas, as quais constam do balanço por seu valor de aquisição, mas cujo valor de mercado poderá ser muito superior no momento da venda. Do lado do passivo, existem as exigibilidades que, por sua natureza, não constam do balanço. Representam o "passivo oculto", e um exemplo típico é o passivo trabalhista da empresa, isto é, o total das indenizações que a firma teria de pagar aos seus empregados, no caso do encerramento de suas atividades. Antes da instituição do Fundo de Garantia do Tempo de Serviço (FGTS), no fechamento da empresa, era freqüente a total absorção dos seus valores patrimoniais por essa responsabilidade trabalhista, o que tinha por consequiência o desestímulo aos investimentos industriais. Atualmente, essa responsabilidade tende a ficar cada vez mais reduzida, na medida em que os empregados optem pelo Fundo, havendo para a empresa apenas uma obrigação adicional de $10 \%$, em relação às quantias depositadas na conta de cada empregado.

\section{Valor pela projeção de lucros passados}

O valor da empresa, de acordo com este método, é determinado pela multiplicação do lucro anual pelo número de anos, ao fim dos quais, deseja-se o retorno total do investimento realizado. $\mathbf{E}$ um processo em boa parte empirico, mas bastante divulgado e utilizado, podendo ser representado pela seguinte formula:

$$
V=L \times n
$$

onde $V$ é o valor da empresa; $L$ é o lucro líquido do último ano ou o lucro médio anual de certo número de anos anteriores; $n$ é o número de anos durante os quais se deseja a amortização do investimento, podendo variar, normalmente, entre cinco e 15, para inversões industriais.

O número de anos para o retorno do capital empregado é conhecido tradicionalmente como o periodo de pay back, podendo ser representado pela equação seguinte:

$$
\text { pay back = investimento/lucro anual }
$$

O vạlor da empresa é representado aqui pelo investimento, dependendo, portanto, do lucro anual e do periodo durante o qual se deseja seu retorno. Esta metodologia introduz um conceito dos mais importantes, isto é, que o valor da empresa é função exclusiva do seu lucro e não mais é determinada por seu valor patrimonial.

\section{Valor das ações}

Para uma sociedade anônima, cujas açōes tenham uma boa negociabilidade em Bolsa, é relativamente fácil calcular-se o valor total da empresa, multiplicando o número total das açōes que constituem o seu capital realizado pelo preço da ação, baseado na cotação do dia. Esse produto então seria o valor de empresa no mercado acionário. Não se trata, obviamente, de seu valor real. As cotaçōes podem se encontrar em nivel muito baixo, motivado por fatores conjunturais, por exemplo. De outro lado, não seria possivel adquirir a em. presa pelo valor assim calculado, pois, à medida que aumentasse a procura das açōes, certamente subiria também a sua cotação. Finalmente, para se obter o controle da empresa, é necessário apenas a aquisição de uma determinada porcentagem de seu capital social, dependendo da distribuição existente das ações da empresa. Entre nós, é extremamente rara a obtenção do controle de uma empresa por compra aberta em Bolsa de Valores.

\section{Valor atual de lucros futuros}

Determina-se, por esse método, o valor da empresa em um dado. momento, unicamente em função de seus lucros futuros. $\mathrm{E}$ processo mais utilizado no campo da engenharia econômica e amplamente empregado como a técnica mais recente para análise de investimentos. Em comparação com o processo exposto no item 3, o lucro passado é desconsiderado, levando-se em conta somente o potencial futuro de lucratividade da empresa. Essa conceituação é típica, aínda, da análise de engenharia econômica, pois, lucros passados não podem ser considerados como parâmetro certo para avaliar a rentabilidade futura, bastando, para confirmá-lo, que ocorram variações na condução dos negócios da empresa, o que é corriqueiro em qualquer tipo de economia. Em apoio, pode-se afirmar, que uma boa lucratividade passada ou atual, não implica necessariamente sua continuidade futura, especialmente se considerarmos a acelerada evolução tecnológica e conseqüente obsolescência a que está sujeito o setor industrial. São conhecidas as circunstâncias em que determinados projetos indus- 
triais tornaram-se economicamente gravosos, durante o próprio prazo de sua implantação, face a mudanças tecnológicas de processo e mutações do próprio mercado consumidor. Portanto, é válido e mesmo recomendável o método que considera a projeção futura dos lucros futuros de empreendimento, durante a vida útil dos investimentos efetuados ou a efetuar.

Adotando-se os preceitos da matemática financeira, os lucros futuros, projetados, são descontados para seu "valor presente" ou atual, computando-se o custo de oportunidade do capital sob a forma de uma taxa de juros de i\% ao ano. No caso dos lucros anuais serem iguais, calcula-se o valor atual do empreendimento pelo desconto da respectiva série anual uniforme de lucros, com auxílio das conhecidas tabelas de juros compostos.

A título de exemplo, o quadro 1 fornece fatores que, multiplicados pelo lucro anual, resultam no valor presente ou atual da empresa, computandose $o$ custo do dinheiro a diversas taxas de $\mathbf{i} \%$ ao ano.

Quadro 1 - Fatores multiplicadores do lucro anual para determinação do "valor atual" da empresa

\begin{tabular}{l|ccc}
\hline $\begin{array}{c}\text { Perído de } \\
\text { amortização ou } \\
\text { de retorno do } \\
\text { investimento }\end{array}$ & $\mathrm{i}=8 \%$ a.a. & $\mathrm{i}=12 \%$ a.a. & $\mathrm{i}=20 \%$ a.a. \\
\hline 5 anos & 3,993 & 3,605 & 2,991 \\
10 anos & 6,710 & 5,650 & 4,192 \\
\hline
\end{tabular}

Assim, se um empreendimento, cuja vida útil é de 10 anos, promete um lucro líquido anual de um milhão de cruzeiros durante esse mesmo período, e se ao fim do $10^{\circ}$ ano o seu valor residual for considerado igual a zero, isto é, sua amortização faz-se integralmente, durante os mencionados 10 anos, então o seu valor presente ou atual será de Cr\$ 6.710 milhōes, considerando-se sempre uma remuneração do capital à taxa de $8 \%$ a.a. Atente-se ainda para o fato de que, sendo todo $o$ investimento original recuperado em 10 anos, o custo da depreciação já foi deduzido.

Para a situação brasileira, essa metodologia é conveniente, pois permite o cálculo de valores, e da rentabilidade, em termos reais, isto é, em ter- mos de moeda estável. Assim, não há necessidade de se computar, a título de previsão, a taxa anual de inflação. Isso explica-se facilmente, pois o "valor atual", por definição, é dado pelo valor da moeda no momento em que o investimento é realizado. O lucro anual também é calculado em função do valor da moeda no instante de sua inversão. Se atualizarmos o lucro anual futuro com uma taxa média de inflação projetada, teremos de dividir esse mesmo lucro anual por essa mesma taxa, para o cálculo de seu valor presente. Em outras palavras, esse método permite ignorar a inflação, pois toda a análise é feita em moeda constante. Não haveria mesmo qualquer modificação dos resultados, caso inflacionássemos os lucros em primeiro lugar e depois os desinflacionássemos novamente.

Para se obter um lucro anual liquido de um milhão de cruzeiros, como foi exemplificado, será obviamente necessário que a empresa acompanhe, com seus preços, a conjuntura inflacionária. Na hipótese otimista de ser possivel realizar futuras reduçōes de custo, em virtude de economias de escala na produção, o valor real desse lucro seria mantido, ainda que os preços não acompanhem futuramente a taxa de inflação. $O$ cálculo desse lucro líquido pressupōe que o custo da manuten. ção do capital de giro próprio tenha sido deduzido antes do resultado obtido.

\subsection{RELAÇÃO VALOR/LUCRO}

Existe uma relação valor da empresa/lucro (V/L) para os investimentos a longo prazo, análoga à relação preço/lucro $(\mathrm{P} / \mathrm{L})$, bastante conhecida na análise do valor das açōes negociadas em Bolsa. A circunstância que diferencia essas duas relações consiste em que a relação $\mathrm{V} / \mathrm{L}$ pressupōe, para o seu cálculo, a existência do custo do capital à taxa de $\mathrm{i} \%$ a.a. A relação $\mathrm{P} / \mathrm{L}$ para açōes apenas significa que seu preço é de $x$ vezes o lucro anual, sem considerar o custo do investimento em $x$ anos, durante os quais a soma dos lucros anuais pagaria o preço da ação, e isso evidentemente no caso do lucro do último ano repetir-se durante os $x$ anos futuros, o que é mera suposição.

$O$ quadro 2 a seguir fornece o número de anos que são necessários para amortizar um investimento, com a remuneração do capital empregado variando entre 3 e $8 \%$ a.a., para relações $\mathrm{V} / \mathrm{L}$ igual a 5,10 e 15, isto é, valores da empresa iguais a 5,10 e 15 vezes o seu respectivo lucro anual previsto (série anual uniforme de lucro). 
Quadro 2 - Número de anos necessários para amortizar um investimento com a taxa de juros de i \% a.a., para diversas relaçóes $\mathrm{V} / \mathrm{L}$.

\begin{tabular}{c|ll|l}
\hline i & V/L=5 & V/L=10 & V/L $=15$ \\
& & & \\
\hline & & & \\
$3 \%$ a.a. & 5,5 anos & 12 anos & 20 anos \\
$4 \%$ a.a. & 5,8 & 13 & 24 \\
$5 \%$ a.a. & 6 & 14,5 & 29 \\
$8 \%$ a.a. & 6,6 & 21 & $\infty$ \\
\hline
\end{tabular}

Assim, por exemplo, desejando-se um retorno de $8 \%$ a.a. serão necessários 21 anos para amortizar totalmente o investimento, ou seja, o valor de uma empresa que tenha custado 10 vezes o seu lucro anual futuro. Investimentos sujeitos a obsolescência rápida apresentam um $\mathrm{V} / \mathrm{L}$ mais reduzido, exigindo elevados lucros anuais em relação ao investimento, a fim de justificar sua viabilidade econômica.

\section{Conclus̆o}

A rápida evolução conjuntural, quer do ponto de vista mercadológico, quer em virtude das constantes transformações da tecnologia empregada na produção, exige um estudo diferente do tradicional, constituindo nova problemática da determinação do valor de uma empresa. Os métodos patrimoniais são úteis como referência inicial e para a fixação de eventuais valores residuais. Evidentemente continuam sendo de grande relevância para a apresentação de garantias reais, junto às instituiçōes de crédito. Já, na conceituação atualizada do administrador de empresas, o valor da empresa é unicamente função de seu potencial futuro de lucros. Em decorrência desse conceito, a empresa, sem adequadas perspectivas de rentabilidade, tem seu valor grandemente depreciado. Por outro lado, as empresas, cujo potencial de lucro tende a se concretizar num futuro previsivel, têm seu valor aumentado, superando amplamente suas avaliações patrimoniais. A determinação do valor da empresa transformou-se, assim, em um processo dinâmico, sob a responsabilidade e o controle de seus administradores. 